\title{
MIRAR Y ESCUICHAR EN LA CIUDAD: ASPECTOS POLÍTICOS DE LA VISIÓN Y LA AUIDICIÓN EN REPÚBLICA VIII Y IX
}

\author{
María Cecilia Fernández Rivero \\ Universidad Nacional de Córdoba \\ mariacecilia1420@yahoo.com.ar
}

\begin{abstract}
La concepción platónica de las experiencias visual y auditiva en un doble nivel (sensible y noético) repercute en su propuesta educativa y política, expresada, entre otros diálogos, en República. Un estudio filológico de estos campos semánticos en el Libro VIII e inicio del Libro IX de República permite postular que, para el ateniense, los cambios en las formas de la polis están ligados a cambios en los modos de ver y oír humanos. Así, el desplazamiento puede producirse desde una mirada y audición profundas a una mirada y audición superficiales, desde un oír- ver unitarios a múltiples, o del ver y oír al no-ver ni oír. En todos los casos, este desplazamiento tiene como correlato un desplazamiento en las formas de organización de la polis.
\end{abstract}

Platón / República / Visión / Audición / Ciudad

\section{TO LOOK AND LISTEN IN THE CITY: POLITICAL ASPECTS OF THE VISION AND HEARING IN REPUIBLIC VIII AND IX}

The Platonic conception of visual and auditory experiences on a double level (sensible and noetic) has an impact on his educational and political proposal, as expressed in the Republic among other dialogues. A philological study of these semantic fields in Book VIII and the beginning of Book IX of the Republic allows us to postulate that in the Athenian's view changes in the forms of the polis are related to changes in human ways of seeing and hearing. Thus, this displacement may occur from deep to superficial sight and hearing, from unitary to multiple sight-hearing, or from seeing-hearing to not-seeing-hearing. In all these cases, this displacement has a correlate in a displacement of the ways the polis can be organized.

Plato / Republic / Vision / Hearing / City 


\section{Introducción}

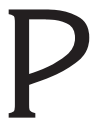

uede pensarse que el despliegue de las experiencias visual y auditiva se presenta, en la perspectiva platónica, en un doble nivel: uno, sensible, y otro, que accede a la estructura profunda de la realidad; una experiencia cognoscitiva plena y filosófica implica el tránsito por ambos niveles. La experiencia no-filosófica consiste no en transitar el primer nivel (absolutamente necesario, en cambio, para la experiencia epistemológica y vital del hombre), sino en anclarse en él y no continuar el recorrido ${ }^{1}$.

Si aceptamos esta premisa para interpretar la concepción platónica de la visión y la audición, se vuelve legítimo preguntarnos por sus consecuencias en la propuesta educativa y política platónica, expresada fundamentalmente en República, Político y Leyes ${ }^{2}$. En este sentido, un recorrido filológico acotado a los campos semánticos visual y auditivo en el primero de estos diálogos, puede constatar la coincidencia de la tematización de la visión y/o de la audición en el diálogo entre los personajes, con momentos nodales de la discusión política, y por lo tanto la imbricación de los campos semánticos de la visión y la audición con los de la vida política. Así sucede durante la discusión de la educación de los gobernantes (libros II y III); la determinación de la justicia como finalidad de la organización social (libro IV); la figura del filósofo y su valoración dentro de la comunidad (que incluye la distinción entre filósofo y "filodoxos" del libro V, la naturaleza y educación del filósofo de los libros VI y VII, y la actitud de la comunidad hacia él descripta también en el libro VII); finalmente, la degradación progresiva de las distintas posibilidades de organización política (libros VIII y IX). De este modo pueden delimitarse cuatro aspectos principales de la discusión política en que los modos de ver y oír adquieren relevancia: 1) La mirada y la audición de los interlocutores del diálogo, en relación con la manifestación de la polis ideal en el discurso; 2) La mirada y audición "profundas" como cualidades que definen al gobernante y a la polis justos; 3) La función de la audición y la visión en la educación de los ciudadanos; 4) La degradación de los modos de ver y oír como generadora de la degradación en las formas de construcción política ${ }^{3}$.

1 Cf. Fernández Rivero (2015), que analiza esta hipótesis en los diálogos Timeo, Fedro y Simposio; MERKER (2003), sobre la relación entre visión y exilio en Timeo, Fedro y República; Napolitano (1994), sobre la visión como metáfora del conocimiento en Platón; PAquET (1973), sobre los verbos de visión y su utilización en un contexto de objetos trascedentes.

2 Cf. Catenaro, 2013: pp. 17 y ss: para él los motivos fundamentales de la República continúan tanto en el Político como en las Leyes; la relación entre los tres diálogos, por otro lado, sólo es posible si se confiere a la República carácter político (Ibid.: 21).

3 Cf., por ejemplo, II, 376 a y ss (sobre la educación de los gobernantes); IV, 421 b-c, sobre la fundación de la ciudad en el diálogo y la mirada y audición de los interlocutores; las alegorías sobre la educación, libros VI y VII. 
Si bien el problema de la relación entre visión y conocimiento filosófico en la República ha sido muy estudiado, en general estos estudios se han centrado sobre todo en la cuestión, precisamente, del vínculo visión-conocimiento -en particular en las tres analogías de los Libros VI y VII, y especialmente en la alegoría de la caverna- sin tener en cuenta como parte de su objetivo los alcances prácticos de este vínculo, que atañen a la propuesta política platónica ${ }^{4}$.

Z. Hitz (2010: 105 y ss) llama la atención sobre el error de dejar de lado la teoría política de la República (entendiéndola como un diálogo que discute exclusivamente la elección de vida individual), ya sea en la descripción de Kallipolis o en la crítica de los libros VIII y IX ${ }^{5}$. Al mismo tiempo, señala que la filosofía negativa o crítica de la República es un tópico más bien descuidado, apuntando al predominio creciente del elemento apetitivo como la causa de la degradación en las distintas politeias del libro VIII. J. Annas pone el centro en la problemática de la disolución de la ciudad a través de una pérdida progresiva de su unidad (1981: 302). En este sentido, creemos que nuestra perspectiva representa un aporte complementario para entender la mirada platónica sobre el proceso relatado en los libros VIII y IX, en el marco de la crítica que recupera la noción de pensamiento político en la República, pero a la vez busca precisar la relación entre este pensamiento y el planteo ético y pedagógico propio de este diálogo.

4 En este sentido, las propuestas que han tenido en cuenta estos alcances en mayor medida son la de L. NAPOLITANO, que señala la función de la vista en tanto actividad comunicativa (1994: 57 y ss.), y la de A. MERKER, cuyo análisis se contextualiza en la perspectiva de la situación humana definida como exilio (2003: 13 y ss). Por otro lado, respecto de la categoría del "oír", el estudio de E. Moutsopoulos sigue siendo una referencia en lo que concierne a la relación entre música y educación, en particular en Leyes (Cfr. MoutsopouLos, 1959: 227-319). Más recientemente, y siguiendo la línea abierta por Moutsopoulos, M.C. Di Giaimo plantea algunas cuestiones sobre la equivalencia entre educación musical y comprensión en República y Leyes (Di Gialmo, en CoRnavaca y otros, 2006: pp. 91 y ss). En lo que respecta a la audición de discursos y su relación con la verdad, cf. SANTA CRUZ: 2007. El abordaje del problema de las percepciones visual y auditiva en conjunto y en relación con el contexto político, en cambio, es una línea de análisis no tan desarrollada.

5 Cf. también Catenaro: 2013, sobre la recuperación de la centralidad del pensamiento político en Platón, y la relación ética-política. AnNAs, por otro lado (1981, 1999), propone la recuperación de la interpretación antigua del diálogo, que da prioridad al argumento ético por sobre el político; sin embargo, señala la aparición en la República de algunos principios políticos generales, dentro del marco estructural ético, que se exploran de modo más concreto y ligado al contexto histórico en el Político y las Leyes (1999: pp. 88-95). En otra línea se sitúan JAEGER (1957), HAVELOCK (1983) y ReALE (2002: 53-54), que discute la perspectiva teórica de Havelock, pero acuerdan en que el tema principal de la República es, ante todo, la educación. Las distintas líneas pueden considerarse complementarias, en cuanto el peso en el diálogo de las dimensiones ética y educativa es evidente, pero esto no debería llevar a invisiblizar la dimensión política. 
De los cuatro aspectos arriba señalados, proponemos entonces delimitar nuestro recorrido filológico al Libro VIII, dominado por la tensión entre perspectiva metafísica e histórica ${ }^{6}$, y algunos pasajes del Libro IX ${ }^{7}$. Podemos postular que, para el ateniense, los cambios en las formas de la polis están ligados a cambios en los modos de ver y oír humanos. La degradación de las formas de organización política griegas se plantea, en el entramado discursivo, ligada a un cambio en las formas de oír (generación del hombre timocrático, 548 e y ss; 549 d y ss), de ver (generación del hombre oligárquico, 553 c- 554 b), y de ambos conjuntamente (generación del hombre democrático, 559 d-e; descripción del hombre tiránico, 568 c579 c); el desplazamiento puede producirse desde una mirada y audición profundas a una mirada y audición superficiales y sin capacidad de discernimiento, desde un oír- ver unitarios a múltiples, del hecho del ver y oír al no-ver ni oír, e incluso al reemplazo de la visión y audición tanto eidéticas como sensibles por la visión onírica o la audición en el marco del espectáculo ${ }^{8}$. En todos los casos, este desplazamiento tiene como correlato un desplazamiento en las formas de organización de la polis.

6 Cf. Baker (1960: 277-283); Annas (1981: 295).

7 A su vez, la interpretación sostenida a través del análisis de los campos semánticos propuestos en esta sección del diálogo, se sustenta también en los ecos que el propio diálogo deja ver de momentos anteriores de la conversación, lo que será oportunamente señalado a lo largo del presente trabajo. En ese sentido, puede decirse que el diálogo presenta una estructura de "ayudas", tanto con remisiones a otros pasajes del diálogo como omisiones que remiten al "afuera" de éste, como sostiene VEGETTI (1999: 30 y ss), siguiendo a su vez a SZLÉZÁK (1997).

8 El relato de la generación de la tiranía se estructura de manera diferente al de las otras politeias, empezando porque, mientras el régimen político se discute al final del libro VIII, la descripción del carácter tiránico (su par) se reserva para el comienzo del libro IX y sirve de nexo para volver de modo fuerte a la cuestión inicial del diálogo sobre la vida justa o injusta y su relación con la felicidad (que si bien se enuncia al inicio de la conversación del libro VIII, no se retoma hasta la aparición de la tiranía). Muchos comentaristas han notado esta diferencia, entre ellos J. Annas (1981: 302 y ss), para quien el opuesto "lógico" del estado ideal, por su disolución en la multiplicidad, está representado más bien en el estado democrático, y el tiránico se pone en discusión precisamente para volver a la cuestión de la contraposición entre el modo de vida "más injusto" o "más justo". La tiranía, por lo tanto, será comentada en la última sección del artículo, solo para señalar algunos elementos que pueden resultar significativos desde nuestra perspectiva. 


\section{De la Edad de Oro a la timocracia}

El Libro VIII se inicia con la continuación del diálogo entre Glaucón y Sócrates, en que se sintetizan los caracteres principales de la polis ideal, "construida" en el discurso, en los libros II-V, para volver, después de la reflexión sobre la educación del filósofo en los Libros VI y VII, al punto en que Sócrates había prometido hablar sobre cuatro constituciones políticas ( bra ahora, en el contexto de $544 \mathrm{c}-\mathrm{d}$, en el que se presentan desde una perspectiva histórica:

[...] la que es elogiada por todos, la misma de Creta y Lacedemonia; y la segunda y elogiada en segundo lugar, llamada oligarquía, constitución política llena de muchos males; la democracia, que llega a ser diferente de ésta y le sigue; y la "noble" tiranía, que se diferencia de todas éstas, cuarta y última enfermedad de la polis.

Para Annas (1981: pp. 295 y ss), el hecho de que Platón reconozca cuatro "tipos" de estado injusto, admitiendo al mismo tiempo que existen tipos de Estado que no encajan en esta clasificación (544 c-d), implica que ésta es un esquema a priori, es decir, un intento de delimitar cuatro formas esenciales de injusticia en la polis. Pero al mismo tiempo, la descripción de algunas de estas formas a partir de la experiencia histórica propia (como la timocracia, en el pasaje citado arriba, caracterizada como la forma de gobierno de Creta y Lacedemonia, o los rasgos atenienses que podrían verse en su descripción de la democracia ${ }^{9}$ ) muestra que Platón apela, de algún modo, a la experiencia para confirmar su "teoría"10. Sin embargo, el diálogo no sería claro respecto de cuándo se asume una u otra perspectiva. En este sentido, creemos apropiado hablar de "tensión": tan pronto la descripción parece referirse a lo que de hecho ha sucedido, como a lo que podría suceder.

A lo largo de esta descripción, la preocupación de los interlocutores estará centrada, por un lado, en la contemplación ${ }^{11}$ de las distintas politeiai y el carácter de los hombres con ellas relacionados, para determinar cuál

9 Sobre este segundo punto, sin embargo, la misma J. Annas expresa sus reservas en su trabajo posterior Platonic Ethics: Old and New: la República no diría demasiado sobre su contexto político, a diferencia de Político y Leyes (Annas, 1999: 77-78).

10 Cf. también BAKER (1960: 277), el diálogo describe regímenes existentes, enfermos en la perspectiva de Platón. Esto no significa, sin embargo, que intente trazar una secuencia histórica; aunque la descripción toma una forma histórica, Platón no imagina los acontecimientos como una serie histórica (Ibid.: 283).

11 En este sentido, vale señalar la existencia de un conjunto de verbos de visión analizados por Fernández Rivero (2015) como connotativos de la visión profunda en Timeo, Simposio 
de ellos es el más justo y cuál el más injusto y en qué modo se relaciona esta cualidad con la felicidad ${ }^{12}$; por otro lado, se preguntarán por la forma en que un régimen político va engendrando a otro (y correlativamente, un tipo de ciudadano o gobernante va mutando en el mismo sentido), desde un pasado mítico en que prevalece la politeia aristocrática ${ }^{13}$. La pregunta es, en este último sentido, cómo una politeia justa se transforma ( $\mu \varepsilon \tau \alpha \beta \alpha \dot{\alpha} \lambda \lambda \varepsilon$, $545 \mathrm{~d} 1$ ), al pasar sus gobernantes del pensamiento común (ómovooṽvtos,

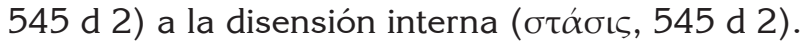

En respuesta a esta pregunta aparece el relato de las Musas (545 e 1 y ss), que es así, como lo señala $M$. Meulder, un relato de orígenes, de "cómo algo sucedió por primera vez"14. El relato mítico provee un fundamento cosmológico y matemático para el inicio del proceso de disgregación de la polis armónica: presenta el nacimiento, entre los guardianes, de jóvenes de constitución no adecuada para el gobierno, debido al desconocimiento, por parte de los gobernantes, del número apropiado para la generación humana armónica ${ }^{15}$. La característica de aquellos será, "aun

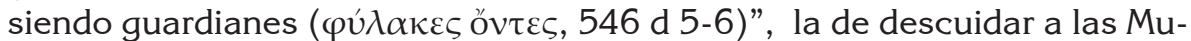
sas, "teniendo a la música en menor estima de la debida" ( $\pi \alpha \varrho$ ' ह̌ $\lambda \alpha \tau \tau o v$

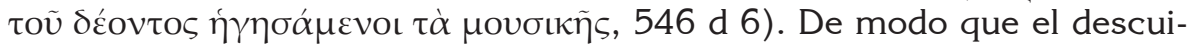
do de la música, entendida desde su vínculo con las Musas, es la primera señal del próximo cambio de constitución política, señal que contradice la cualidad de "guardianes" que corresponde a los próximos gobernantes. La consecuencia inmediata (todavía en el plano del relato mítico) será la incapacidad de distinguir adecuadamente las razas de oro, plata y bron$\mathrm{ce}^{16}$, lo que provocará una "anomalía inarmónica" en las almas de los futuros guardianes. Así, comenzarán a acumular tierras y casas y a hacer

y Fedro, y que aparecen en el contexto de "mirar en el discurso" en los libros anteriores de

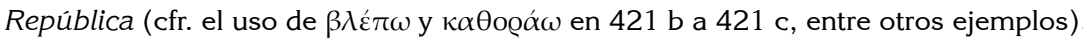

12 Cf. Pl. R. 545 a-c. Pueden observarse en el pasaje la utilización reiterada de verbos de visión para referirse a la descripción de las politeiai y hombres que va surgiendo del discurso:

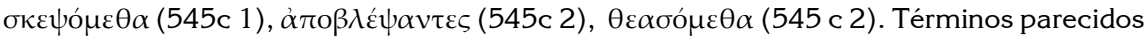
aparecen en el libro IV para referirse a la mirada de los interlocutores sobre la justicia en la

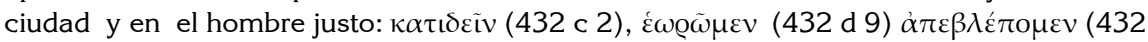
е 1), $\dot{\alpha} \pi \varepsilon \sigma \kappa о \pi о \tilde{u} \mu \varepsilon v(432$ e 2), etc.

13 Entendido este término en sentido etimológico.

14 Algo que en el plano de la discusión filosófica previa parece estar en el futuro (la ciudad gobernada por el rey filósofo) se transporta a un pasado mítico, del cual no puede darse cuenta en forma verificable, y en cambio es la palabra de las Musas, que tienen poder de omnisciencia tanto sobre el pasado como sobre el futuro la que puede referir y explicar ese pasado (Cf. MEULDER, M., 1992: 152-55).

15 Para un análisis detallado del significado de este número y sus implicancias matemáticas, cf. GAISER (1998).

16 Cfr. Pl. R. 415 a y ss.

Argos 40 (2017) ISSN 0325-4194, pp. 121-141 
sirvientes a los amigos libres (547 a-c). Éste es el momento del cambio ( $\mu \varepsilon \tau \alpha \dot{\beta} \beta \alpha \sigma \iota \varsigma, 547$ с 5).

La descripción del nuevo régimen corresponde ya al plano de la discusión filosófica, en que Sócrates y Adimanto recuperan sus voces: al ser intermedio entre la aristocracia y la oligarquía, imitará en parte a uno y a otro. Es en la acumulación de riquezas en lo que imita al segundo, y la causa es haber sido educados por la fuerza y no por la persuasión, debido,

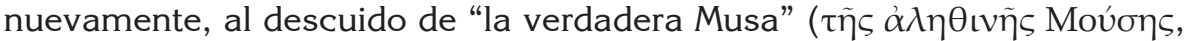
548 b 8), "la que se acompaña de discursos y de filosofía" ( $\tau \tilde{\eta} \varsigma \mu \varepsilon \tau \dot{\alpha} \lambda$ ó $\gamma \omega \nu$

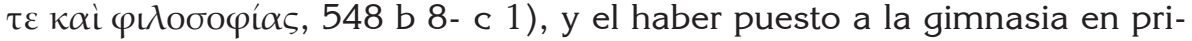
mer lugar respecto a la música (548 c 2 ).

La afirmación de que estos hombres pusieron en "primer lugar" la gimnasia con respecto a la música, remite claramente a Pl. R. 376 e y ss, en que los interlocutores han discutido la educación de los guardianes, y han acordado que ésta debe comenzar con la gimnasia para el cuerpo y la música para el alma (376 e 3-4), que comienza por la música antes que

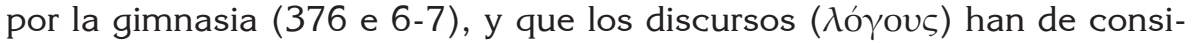
derarse como parte de la música $(376 \text { e } 9)^{17}$. Por otro lado, la aclaración de "verdadera", referida a la Musa, y reforzada después por el vínculo que se establece entre música, discursos y filosofía, puede entenderse mejor en relación con Pl. Ti. 47 c- $\mathrm{e}^{18}$, en que se describe la finalidad con que el Demiurgo dota al hombre de ojos y oídos. En relación con estos últimos,

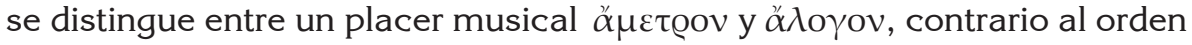
interior del alma, y el que se relaciona con el ritmo y la armonía, y produce discursos filosóficos. Está claro que los gobernantes timocráticos se alejan de este tipo de audición ${ }^{19}$, que aúna ritmo, armonía y discurso y que educa a través de la persuasión. El alejamiento de las Musas se produce así tanto en el nivel de la educación inicial de los guardianes, en su infancia, en que la música debe comenzar su orientación hacia lo bello, como en el nivel de la visión y audición eidéticas, propia de los reyes filósofos que han recorrido todas las etapas educativas propuestas en los libros VI y VII.

El resultado de este alejamiento es una $\pi 0 \lambda \iota \tau \varepsilon i ́ \alpha$ en la que bien y mal se hallan mezclados, pero en la que predomina el deseo de ser venerado, y los gobernantes son los hombres fogosos, más bien que los sabios. En

17 Sobre qué tipo de discursos y según qué parámetros pueden ser considerados verdaderos, cf. Santa Cruz (2007).

18 En la introducción de este diálogo muchos estudiosos (cf. RACIONERo, 1998: 29; ANNAS, 1999: p. 90; FRONTEROTTA, 2003: p. 11; Rowe, C., 2010: p. 15) ven una referencia a la República, y por lo tanto una intención de Platón de vincular ambos diálogos. Para el análisis del pasaje, cf. FERnÁndez Rivero (2015: 68 y ss).

19 Otro nivel de audición, no filosófica, sería la que se critica en Pl. R., 376 a y ss, así como en otros pasajes del libro VIII. 
consonancia con la metodología previamente acordada, a la descripción

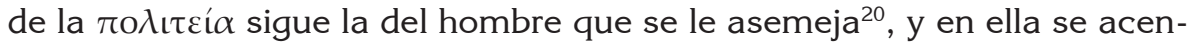
túa el interés puesto por los interlocutores en la cuestión de la música: este hombre debe ser "más obstinado", pero también "de algún modo más

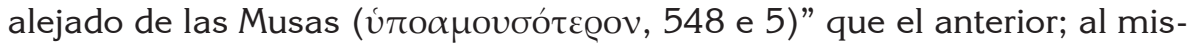
mo tiempo, subrayando la ambigüedad propia de este régimen, se lo califica de "amigo de las Musas y de las audiciones, pero para nada retórico"

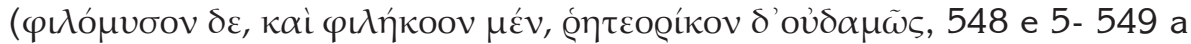
1). Así, hombre y ciudad se asemejan, tal como han anticipado los interlocutores al iniciar su discusión, y la característica principal del hombre timocrático reside en la pérdida de un cierto nivel de audición, que implica cercanía con la verdadera música y con la audición de discursos filosóficos. Conserva el amor por estas audiciones, pero en un grado de alejamiento de lo verdadero. Más adelante, se dice que de viejo amará las riquezas, por faltarle el "mejor guardián": el $\lambda o ́ \gamma o \varsigma$, mezclado con la música, que es

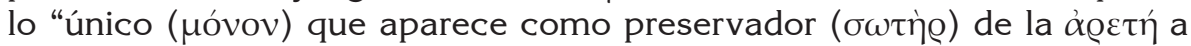
lo largo de la vida" (549 b 6-7) ${ }^{21}$. Si éste es el punto que se destaca en la descripción del carácter del hombre timocrático, del mismo modo ocurre en el relato de su generación. La contraparte de la audición de la "verdadera música", olvidada por este hombre, es la audición de los múltiples rumores que lo llevan al cambio. Así, muchas veces el joven es hijo de un buen padre que vive en una polis no organizada, y escucha ( $\dot{\alpha} \kappa o u ́ \eta, 549$ c 8) a su madre quejarse de que el padre no se cuenta entre los gobernantes; del mismo modo hablan los sirvientes; al salir a la calle, oye (ảkoúcı, 550 a 2) otras cosas de este tipo y ve (ó@ ã, 550 a 2) que los que se ocupan de lo

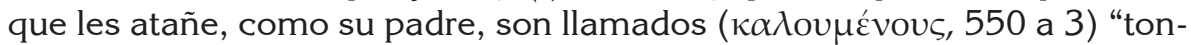
tos", mientras los que hacen lo contrario son honrados. Entonces, "oyen-

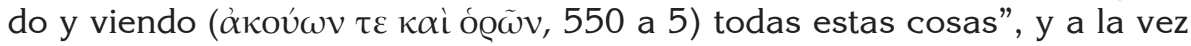

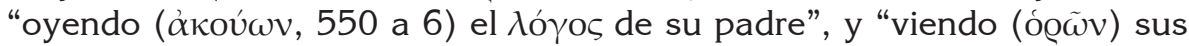

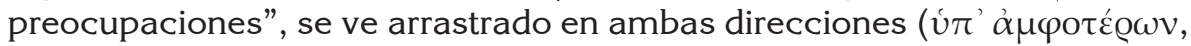

20 Para J. Annas, esta metodología supone un problema, ya que considera que el paralelo persona- ciudad, en el caso de la ciudad justa, es admisible porque se trataría de un par ciudad-individuo totalmente armonizados y unificados; pero que en el caso de la disrupción de esta armonía no se justificaría sostener del mismo modo que hubiera un paralelo exacto entre individuo y ciudad en cuanto a la gradualidad con que esta disrupción se produce. Esto provocaría un cierto efecto de "artificialidad" en los libros VIII y IX (Cfr. AnNAS, 1981: 295). Creemos en cambio que es posible sostener el paralelismo, a través de ciertas marcas de la disrupción que, según hemos postulado, aparecen en el cambio en los modos de ver y oír de los ciudadanos.

21 Cf. Pl. R. 484 d 3, en el libro VI, sobre la función de los guardianes de preservar, vigilándolas

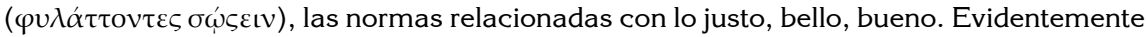
en este plano se coloca la audición de la verdadera música y $\lambda o ́ \gamma o \varsigma$, olvidada por los gobernantes timocráticos. 


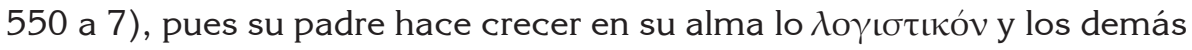

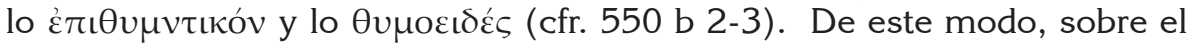
final de esta descripción del tránsito de uno a otro tipo humano, aparecen juntos el ver y el oír. Este ver sólo sensible (ó@ó́ ocupa ese lugar dentro del campo semántico de la visión en muchos diálogos ${ }^{22}$ ) y oír superficial (porque su objeto son los rumores de muchos) se contrapone al oír profundo, en el vínculo con la verdadera música y la filosofía, del que el joven se ha alejado. Al mismo tiempo, el ḋkoúcı v de la verdadera música aparece relacionado con la unidad, mientras que tanto el oír como el ver que motorizan el cambio son dobles, van en dos direcciones entre las que el joven timocrático no es capaz de discriminar ni jerarquizar.

\section{De la timocracia a la oligarquía}

En la descripción del paso de la timocracia a la oligarquía predomina claramente el campo semántico de lo visual. Ya desde el primer momento, cuando los interlocutores consideran completa la descripción del régimen y del hombre timocrático, y del modo en que se produce el cambio, señalan que el modo en que la timocracia se transforma ( $\mu \varepsilon \tau \alpha \beta \alpha i ́ v \varepsilon t, 550$ d 3) en oligarquía -definida en 550 d 1 como la politeia en que los ricos mandan y los pobres no participan del gobierno-, debe ser evidente ( $\delta \eta^{\prime} \lambda \mathrm{ov}$ ) incluso para un ciego $(\tau v \varphi \lambda \hat{\omega}, 550 \mathrm{~d} 6)^{23}$. La causa es la "cámara llena de

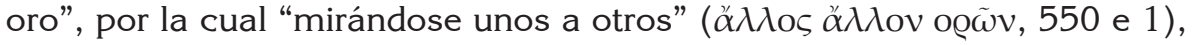
y yendo hacia la emulación ( $\zeta \tilde{\eta} \lambda o v, 550$ e 1), la mayoría empieza a estimar cada vez más la riqueza y menospreciar la excelencia. Hay una contraposición entre la mirada de los interlocutores, que no son ciegos, que saben ver cómo es y cómo cambia una polis de uno a otro régimen, y la de los hombres timocráticos, que ya han perdido un nivel de audición, y que ahora, al perder también un nivel de visión, se transforman en oligárquicos. En lugar de la mirada que permitiría anticipar el cambio en la organización de la polis, ven solamente en el plano sensible (o@ $\tilde{\omega} v)$, con el resultado de la imitación proveniente de la envidia ( $\zeta \tilde{\eta} \lambda o v)$. No olvidemos que $\zeta \tilde{\eta} \lambda$ os puede significar tanto "envidia" como "emulación", y que este último sentido deriva del anterior: es decir, la visión de quien tiene algo que otro no -en este caso, más riquezas- puede llevar a éste a imitarlo. Esta imitación puede tener connotaciones positivas o negativas, aunque en el contexto de los diálogos platónicos las segundas son más frecuentes, ya

22 Cf. Fernández Rivero (2015).

23 La posibilidad de contemplar dentro del discurso es uno de los ejes alrededor de los cuales se construye la discusión sobre la polis en República, como hemos dicho. Cf. Supra, nota 11. 
que su valor social y político se opone al de la filosofía ${ }^{24}$. En este sentido, $\zeta \tilde{\eta} \lambda$ o y $\varphi \theta$ óvo se asimilan, y en la tradición griega, ambos términos se relacionan, según L. Napolitano, con un determinado tipo de mirada escondida, torcida, o que pretende engañar y ver sin ser vista (cf. NAPOLITANO, 1994: pp. 58-67). La veneración y el afán de imitación de los hombres ricos implica, según Sócrates y Adimanto, el menosprecio correlativo de los hombres buenos, lo que lleva a una polis dividida en dos, la de los ricos, que gobiernan, y la de los pobres, que son excluidos del gobierno. Queda así formada la nueva politeia, que se caracteriza por ser doble, por generar zánganos y mendigos, y por permitir el derroche del gobernante (Cf. 550 e- 553 a). El hombre es, por supuesto, semejante a la polis, y la

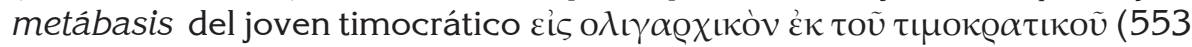
a 6$)$, se produce también a partir de la visión y de la imitación. Primero

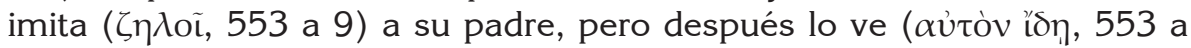
10) perder sus bienes, ser perseguido en los tribunales y desterrado o ejecutado (cfr. 553 a-b), y entonces, atemorizado, entroniza en su alma a lo

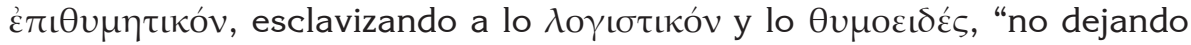

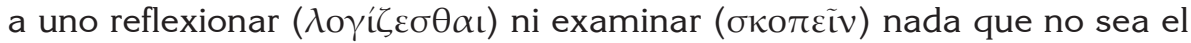
acrecentamiento de la riqueza, ni al otro admirar $(\theta \alpha v \mu \alpha ́ \zeta \varepsilon เ v)$ y venerar $(\tau \mu \tilde{\alpha} v)$ otra cosa que el dinero y los ricos" (553 d 3- 5). Como se ve, el cambio de carácter del joven se da en este caso a partir de la visión. De nuevo aparecen los términos "imitar" y "ver", pero en orden inverso a la

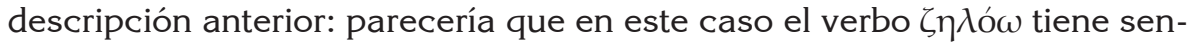
tido positivo, ya que habla de la imitación del joven de su padre timocrático. Sin embargo, recordemos que ya la timocracia incluía un desorden en la jerarquía de las partes del alma, y tenía como objetivo la acumulación de riquezas. La visión de lo que su padre sufre por no participar en la corrupción de la polis, por otro lado, lleva al joven a terminar de invertir las jerarquías de su alma. Curiosamente, entre las acciones propias de cada una de las partes esclavizadas, impedidas por el joven, se mencionan dos

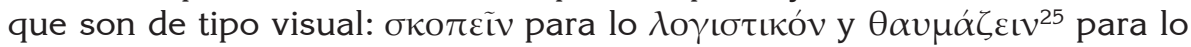

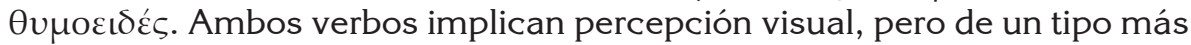
profundo que la del ó@ã $v$, en el primer caso relacionado con la reflexión y en el segundo con la contemplación. En cambio, el joven no ha puesto

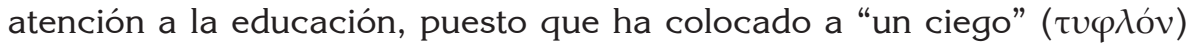

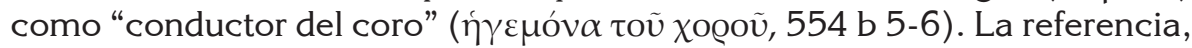
como se ha señalado, es a Pluto, el dios de la riqueza, representado como

24 Cfr.Pl. Leg. 730 e y 870 c, según la interpretación de L. Napolitano (Cf. Napolitano, 1994: 67 y nota 31 ).

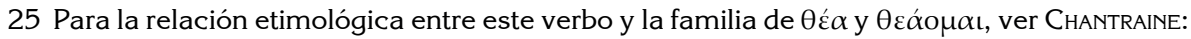
1968. 
ciego $^{26}$, pero no parece casual, dado que la transformación del joven parte de un impacto visual (la visión de lo que ocurre con su padre), para seguir con el cercenamiento de determinados niveles de visión, y terminar ahora

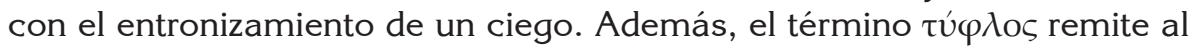
inicio de la conversación, cuando se decía que sólo un ciego podría no ver cómo se produce el cambio de un régimen a otro. Finalmente, el hombre timocrático -luego oligárquico- se he demostrado como tal ciego. Pluto es así la imagen del gobernante oligárquico, contrapuesta a los 'fundadores de la ciudad" en el diálogo.

En efecto, a continuación Sócrates propone a Adimanto que examine (бкó $\varepsilon \varepsilon, 554$ b 7) cómo la falta de educación ha hecho surgir en este hombre los apetitos propios del zángano. Y continúa: “¿Sabes a dónde, habien-

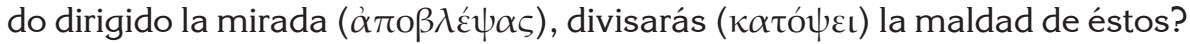
(554 c 4)". La respuesta consiste en mirar hacia la tutela de los huérfanos y hacia cualquier situación que dé a estos hombres la posibilidad de cometer injusticia. La tríada de verbos de visión -además, en sentido ascendente ${ }^{27}$ - atribuida a los participantes del diálogo extrema el contraste entre su capacidad de mirar con agudeza y la ceguera del hombre oligárquico.

El término $\tau v \varphi \lambda o ́ \varsigma$ y el pasaje concreto arriba analizado vinculan, por otra parte, el libro VIII y el libro VI del mismo diálogo. En 484 c 3 y ss, Sócrates propone la analogía entre los guardianes de "lo que sea" y los guardianes de la ciudad. Se pregunta entonces si un guardián debería ser ciego

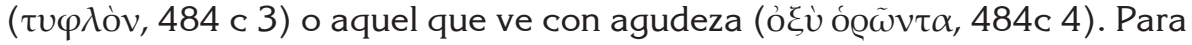
Glaucón es claro que el segundo. Sócrates contesta entonces:

¿Crees que difieren en algo de los ciegos ( $\tau v \varphi \lambda \tilde{\omega} v, 484$ c 6 ) los que están privados realmente del conocimiento de lo que cada cosa es y no tienen en el alma ningún paradigma claro, no siendo capaces,

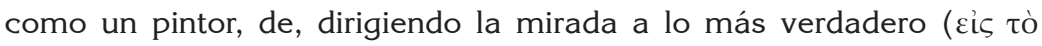

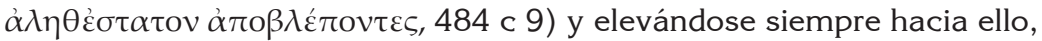
y contemplándolo ( $\theta \varepsilon \omega \dot{\omega} \mu \varepsilon v o l, 484 \mathrm{~d} 1$ ) lo más exactamente posible, instituir así aquí las normas referidas a las cosas bellas y justas y buenas, si es necesario instituirlas, o, estando ya establecidas, preservarlas, vigilándolas?

26 Cf. el mito sobre el nacimiento de Eros en el Simposio (202 a y ss), y la comedia Pluto, de Aristófanes.

27 Estos verbos de visión se reiteran en otros diálogos, con una relación parecida. La función de $\beta \lambda \varepsilon ́ \pi \omega$ y sus derivados como conectores entre el plano de la visión sensible y la visión

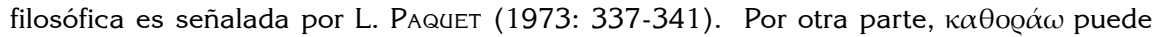
considerarse como un verbo de visión filosófica en la mayoría de los contextos platónicos; es el verbo con el que se expresa el momento de visión última en el Simposio (210 e y ss) y la visión de las almas en el Hiperuranio en Fedro (247 d y ss; 248 c). Cf. Fernández RIVERO (2015: pp. 98-99). 
La metáfora visual, para hablar de los guardianes y del conocimiento, es, como lo señalamos en la introducción, una constante durante todo el diálogo, y se acentúa, en relación con la educación de los guardianes, en los libros VI y VII. El pasaje citado opone al buen gobernante, caracterizado por su visión de lo verdadero, que implica la constitución en la ciudad de las normas justas, y el ciego, identificado con el que carece de este tipo de visión ${ }^{28}$. En este sentido, la calificación del gobernante oligarca como $\tau v \varphi \lambda$ ós aborda la misma dicotomía, no ya desde la perspectiva del gobernante adecuadamente educado, como en el libro VI, sino desde la del ciego puesto en la situación de ser guardián.

Finalmente, y volviendo al libro VIII, la descripción del hombre oligárquico retorna a la cuestión de su disensión interna, y de que no es un

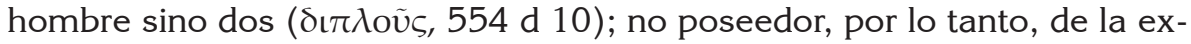
celencia de un alma concorde y armónica (554 e 5). Se vuelve entonces a la idea de la verdadera música, presente en la descripción del tránsito hacia la timocracia, y a la oposición unidad-dualidad, anticipada ya en el relato de las Musas (ver supra). Este hombre, como su polis, no es uno sino dos, y esta división comienza con el alejamiento de una audición musical verdadera, para culminar en la ceguera del gobernante oligárquico ${ }^{29}$.

\section{De la oligarquía a la democracia}

Sobre el final del Libro VIII, se pasa al examen del cambio de régimen y hombre oligárquicos a sus correlativos democráticos. La democracia en este contexto no es vista con connotaciones positivas con los interlocutores; debemos tener en cuenta que se trata de la reacción de una polis ya enferma por la oligarquía ${ }^{30}$. Así, la descripción comienza por su origen: en la polis oligárquica, los ricos "caminan agachados" ( $\varepsilon \gamma \kappa u ́ \psi \alpha \nu \tau \varepsilon \varsigma)$, de

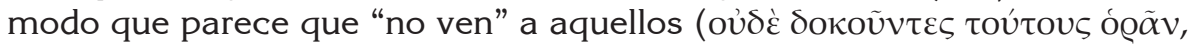
555 e 3-4) -los pobres y otros ciudadanos a los que hieren con su "aguijón"-. Los gobernantes generan mendigos y zánganos entre sus gobernados, y al mismo tiempo vuelven a sus hijos blandos y pocos resistentes a

28 Cf. también Pl. Phdr 270 e 1-2, en que Sócrates caracteriza al ignorante de la dialéctica como ciego $(\tau \cup \varphi \lambda \tilde{\omega})$ y sordo $(\kappa \omega \varphi \tilde{\omega})$.

29 Sobre la disolución de la unidad de la polis, cf. Annas (1981: 302 y ss).

30 Además, como consideran AnnAs (1981: 295 y ss) y otros, la democracia descripta en esta sección corresponde en parte a un relato a priori, y en parte a un relato experiencial (la Atenas contemporánea). En otros diálogos y contextos, la democracia adquiere valor positivo: así, por ejemplo, en Leyes 693 d-e (sobre la necesidad de mezclar monarquía y democracia en el gobierno propuesto por el Ateniense). Por otro lado, en el Político, la democracia que obedece a las leyes es valorada positivamente (Pl. P. 288 e y ss). Cf. Wallach (2001), sobre el arte político como propuesta teórica en República y como propuesta pragmática de gobierno en Leyes y Político. 
las penurias. Después, cuando gobernantes y gobernados se encuentran en el marco de expediciones militares o peregrinaciones religiosas, o se observan ( $\theta \varepsilon \omega \dot{\omega} \mu \varepsilon v o l, 556$ d 1) compartiendo peligros juntos, no serán los pobres menospreciados, puesto que los ricos están menos preparados para esas situaciones. El pobre ve ('ín, $556 \mathrm{~d} 4$ ) al rico en aprietos y piensa que será fácil vencerlo, con lo que la necesidad creada por el gobernante oligárquico, así como su carácter, proveen el fundamento necesario para una "revolución" y cambio de organización política. La democracia nacería entonces cuando los pobres matan a los ricos y establecen un gobierno en que la alternancia en los cargos se da sobre todo por sorteo ${ }^{31}$. Así pues, en el relato del nacimiento de la democracia se produce un contraste visual: Los gobernantes oligárquicos, ciegos, como ya hemos dicho, muestran un nuevo aspecto de su ceguera, al caminar agachados para evitar ver a los pobres. Por otro lado, éstos ven perfectamente las debilidades del régimen, y de esa captación nace el cambio.

En la descripción del régimen democrático el foco está puesto en su capacidad de incluir en sí mismo a todos los modelos políticos posibles, de permitir a cada uno hacer lo que quiera, y en general, de "tratar como igual tanto a lo igual como a lo desigual". En ese marco, es descripto a través de la analogía con un manto colorido: "Tal como un manto colorido ( $\pi$ oเkílov), que tiene bordado toda clase de flores $(\pi \tilde{\alpha} \sigma \iota v \not \alpha v \theta \varepsilon \sigma \iota$

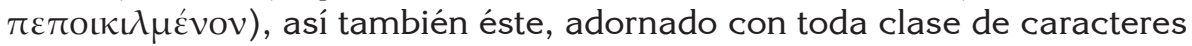

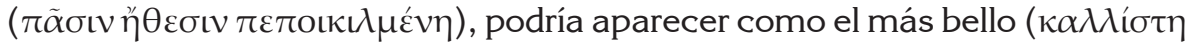
àv paívoıto). Y quizás la mayoría -dije yo- juzgaría también como el más bello a este régimen político, como los niños y las mujeres que contem-

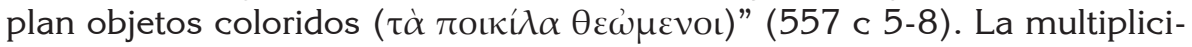
dad de placeres y modelos, sin jerarquía ni ordenamiento entre ellos, que caracteriza a este régimen es mostrada a través de una imagen visual: una multiplicidad de colores y bordados que, por el hecho de su variedad, impactan al que mira como si se tratara de la mayor belleza. Los interlocutores proporcionan a continuación una serie de ejemplos políticos (como la no-obligación de participar de la guerra o de la paz de toda la ciudad, de gobernar o ser gobernado, etc) para llegar al ejemplo de los condenados, que siéndolo, siguen quedándose y algunos paseando como héroes, "sin

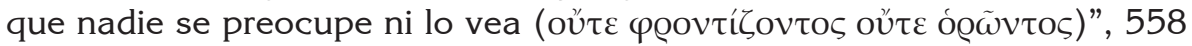
c 7-8. Se trata entonces de un régimen placentero, anárquico y colorido ( $\pi$ о кí $\lambda \eta, 558$ с 5), que asigna igualdad tanto a las cosas iguales como a las desiguales. La apertura y cierre de esta descripción con la imagen de lo "colorido", encierran a la variedad de ejemplos mencionados. Es llamativo

31 Cf. sobre esta división, Rosen (2005: 313). Sobre la consideración de la democracia sobre todo como ruptura de un cierto orden político, y no desde la perspectiva de la valoración de la libertad y la diversidad, cf. Ibid.: pp. 315 y ss. 
el contraste entre la variedad de coloridos y la incapacidad de ver (incluso en el plano sensible) que caracteriza a esta ciudad.

Tal como en las descripciones anteriores, los interlocutores se plantean entonces el origen y el carácter del joven gobernante democrático. En cuanto a su origen, se ha dicho que gusta de rodearse de multitudes de zánganos, capaces de proveerle placeres de múltiples colores y especies, y se deja seducir por toda clase de discursos falsos que se hacen con la acrópolis de su alma, cuando se dan cuenta de que está privada de discursos verdaderos (cfr. 560 b-e). De estos últimos se dice que son "los más excelentes centinelas y guardianes que hay en el pensamiento de los hombres amados por los dioses (560 b 9-10)", en un giro que recuerda a la generación del hombre timocrático a partir del olvido del discurso verdadero (olvido que también se presenta, en el caso del hombre democrático, con la imagen de los lotófagos). El joven termina por ser descripto en los mismos términos que la politeia, como "multiforme ( $\pi \alpha \nu \tau o \delta \alpha \pi o ́ v)$

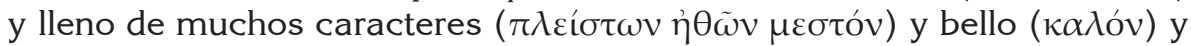

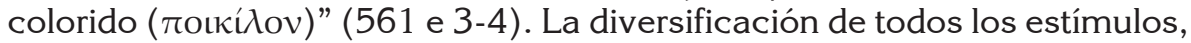
y entre ellos los visuales y auditivos, sin orden ni distinción de jerarquías, distingue entonces a esta politeia.

En este sentido, la sección sobre la polis y el hombre democráticos también recoge ecos de momentos anteriores del diálogo: en al menos dos pasajes del libro V (475 d y ss; 480 a y ss), Sócrates intenta delimitar la

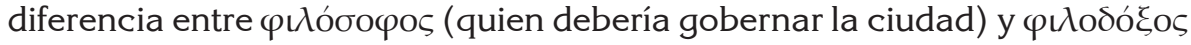
(quien muchas veces gobierna, de hecho, la polis). Mientras el primero se revela como amante solamente del espectáculo de la verdad ( $\tau$ où $\tau \tilde{\eta} \sigma$ $\dot{\alpha} \lambda \eta \theta \varepsilon \dot{\alpha} \alpha \varsigma \varphi \iota \lambda \mathrm{o} \theta \varepsilon \alpha \dot{\mu} \mu \mathrm{ov} \alpha \varsigma, 475$ e 4), el segundo se manifiesta como amante

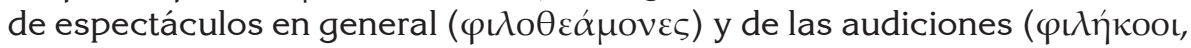
476 b 4). El análisis de los contextos manifiesta dos niveles de visión: uno profundo, vinculado a la unidad ${ }^{32}$, y otro, ligado a la multiplicidad, en el que permanecen los filodóxoi ${ }^{33}$. En la descripción de este segundo nivel,

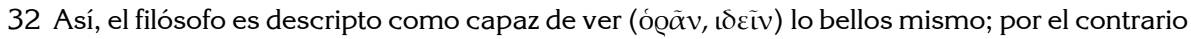
el filodóxos es incapaz (cf. 476 b 4 y ss).

33 La discusión tiene su punto de partida en la identificación como filósofos, por parte de Glaucón, de todos los amantes de espectáculos y audiciones, con referencias a la Atenas

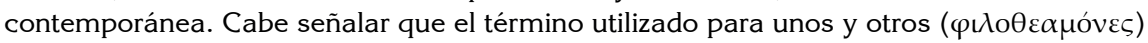
es el mismo; cambia el objeto de la visión y la posibilidad del filósofo de pasar de un nivel a otro (el primer nivel no se descarta, es compartido por ambos). Cf. en este sentido D. MoDRAK (2010: 136): la percepción visual y auditiva no se presenta como negativa, sino como un impulso para filosofar, pero los amantes de visiones y sonidos fallan en captar la conexión entre las bellezas de estos sonidos y visiones y lo bello en sí, i.e., en la perspectiva que hemos asumido, fallan en el reconocimiento de un segundo nivel de visión y audición. Cf. también GRISEI (2004: 282), sobre la confirmación en el libro VI de que la realidad es única, aunque cada nivel represente una superación del precedente. 
se dice que los amantes de audiciones y espectáculos reciben con agra-

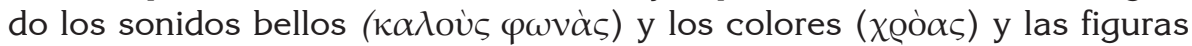

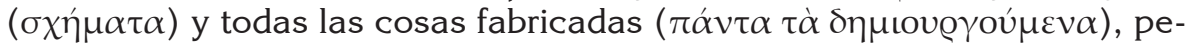
ro son incapaces de recibir de la misma forma a lo bello mismo ( $\alpha \dot{v} \tau o \dot{v}$

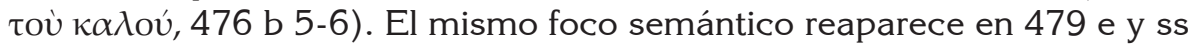

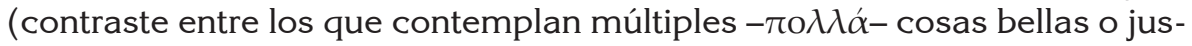
tas y los que contemplan lo justo) y en 480 a y ss (de nuevo la mención a

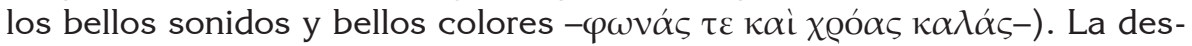
cripción de la atracción que ejerce la politeia democrática a través de la variedad de colores y de formas que presenta remite de algún modo a este contraste, mostrando a los gobernantes democráticos anclados en este segundo nivel de visión, caracterizado ante todo por la multiplicidad colorida.

\section{De la democracia a la tiranía}

La cuarta forma de politeia, la tiranía, se describe también en el libro VIII, pero el carácter del tirano, que le corresponde, se analiza en el libro IX, en conexión con el tema más general, presentado ya en el libro I, de la relación entre los pares justicia-injusticia y felicidad-infelicidad ${ }^{34}$. La descripción de la generación de la tiranía, todavía dentro del libro VIII (564 a y ss) es paradójica: el exceso en el obrar, en cualquier sentido, suele revertir en un cambio en sentido opuesto, según Sócrates, ya se trate de la naturaleza o de organizaciones políticas. En términos de SCHOFiELD (2006: 118), la excesiva libertad lleva a una excesiva esclavitud ${ }^{35}$.

En el relato de la generación de esta cuarta forma de gobierno y del carácter del tirano, que se le asemeja, no encontramos un foco tan marcado sobre el cambio en los modos de ver y oír como en las descripciones anteriores, porque vuelve a ponerse en el centro de la discusión la cuestión más general de la relación entre justicia-injusticia y felicidad-infelicidad, y se acentúa la función, como generador del cambio, del carácter apetitivo del tirano. Sin embargo, hay algunos elementos alusivos, que indicaremos brevemente aquí.

La generación de la tiranía se describe como provocada por las disensiones, juicios y desacuerdos en la polis democrática entre el pueblo y los ricos, disensiones instigadas por los "zánganos", que son los que adminis-

34 La conexión virtud- felicidad es, para J. Annas (1999: 87-95), el eje principal -ético- de la República.

35 Sugiere, por tanto, que Sócrates no está realmente describiendo una democracia sino una anarquía. En su perspectiva, Platón mira a la democracia "desde adentro", más bien que desde una postura teórica, y su intuición del potencial de la democracia para la anarquía genera "una pieza de análisis sociopolítico original y poderosa" (Ibid.: 130). Cf. también BAKER (1960: 296): para él el diálogo describe una anarquía o poliarquía. 
tran la ciudad. La muchedumbre pone a la cabeza un líder, y este líder se transforma en tirano cuando comienza a realizar asesinatos y volverse, de algún modo, un lobo ( 565 d- 566 a). Para conservar el poder se ve obligado a provocar guerras, pobreza, y hacerse de enemigos. El objetivo de conservar el poder implica eliminar a todos sus posibles oponentes de valor, amigos o enemigos:

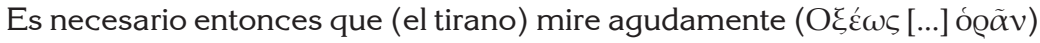
quién es valiente, quién de espíritu noble, quién sensato, quién rico: y es tan feliz, que es necesario para él, lo quiera o no, ser enemigo de todos esos y conspirar contra ellos, hasta que haya purificado la ciudad ( $\kappa \alpha \theta \eta \dot{0 \eta}$

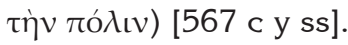

Así, comentan los interlocutores, el tirano procede de modo contrario ( $\dot{c} v \alpha v \tau i ́ o v)$ a lo que hace el médico con el cuerpo, pues el médico quita lo peor y deja lo mejor, y el tirano hace lo inverso en la ciudad ${ }^{36}$. Es curiosa, en el contexto del diálogo, la expresión "mirar agudamente" atribuida al tirano, ya que es una acción que, como hemos visto, se asigna en general al gobernante-filósofo o a los interlocutores en cuanto participantes del diálogo filosófico e instituyentes, a través de él, de la ciudad ideal. Podemos apuntar dos elementos: por un lado, el verbo utilizado, ó@á $\omega$, no es uno de los verbos que característicamente se aplica a la acción de ver en el filósofo o en los participantes del diálogo (más bien $\beta \lambda \dot{\varepsilon} \pi \omega, \dot{\alpha} \pi \mathrm{o} \beta \lambda \dot{\varepsilon} \pi \omega$, $\kappa \alpha \theta$ o@ $\left.\alpha \omega^{37}\right)$. Por otro lado, este verbo está modificado por el adverbio ("agudamente"), ya que es necesaria una cierta penetración para distinguir a los hombres valiosos, y en ese sentido, a lo mejor de lo peor. Sin embargo, la acción resultante (extirpar lo mejor) es la contraria de la que se esperaría de alguien capaz de realizar esa distinción. Podría pensarse que el elemento noético del alma tiene todavía alguna participación en la identificación de los hombres valiosos, pero al encontrarse invertida la jerarquía del alma, la decisión de "extirpar lo mejor de la ciudad" se funda en el elemento apetitivo ${ }^{38}$.

36 La analogía filósofo-médico es también una constante platónica (Cf. Cármides, Gorgias, Fedro, Político). Como muchos estudios han notado, la intención principal en el relato de la tiranía es proponer la figura del tirano como el opuesto exacto del gobernante filósofo (cf. Annas, 1981: 302 y ss). Para la cuestión de la consideración de la estructura de la polis y la terminología médica aplicada a ella en Platón, cf. Levin: 2014.

37 Cf. supra, nota 27.

38 En ese sentido, se presenta el problema -que no vamos a indagar ahora- de que el tirano, aparentemente, conoce lo mejor y voluntariamente lo rechaza. La cuestión debe enmarcarse en la propuesta de tripartición del alma, sobre la que hay diversas líneas de interpretación. Cf. ROWE (2010: 19-20), sobre qué significa hacer mal "voluntariamente" a partir de la introducción de los elementos irracionales del alma en la República. Cf. También Lorenz 
Los otros pasajes que creemos significativos para nuestra perspectiva de análisis se encuentran semánticamente ligados, en el sentido de que parecen presentar el reemplazo (en el caso del tirano) de la visión y audición, incluso sensibles, por experiencias visuales y auditivas ilusorias. En el primero de estos pasajes, el tirano se ve obligado a rodearse de hombres viles, y en esta circunstancia, Sócrates aprovecha para referirse a los poetas trágicos como propagadores de las tiranías, citando un verso de Eurípides en alabanza a los sabios que rodean al tirano. Dice entonces que son ellos quienes "después de alquilar voces bellas, potentes y persuasivas ( $\kappa \alpha \lambda \dot{\alpha} \varsigma$

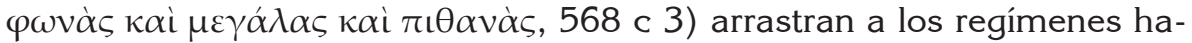
cia las tiranías y democracias", y se los critica por ser cantores de him-

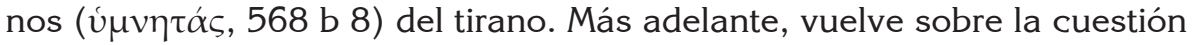
de la nutrición del ejército del tirano, "bello, múltiple, colorido y nunca el mismo (

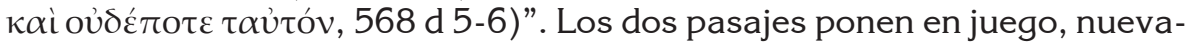
mente, la oposición unidad-multiplicidad que caracterizaba negativamente a la democracia, en los ámbitos de la audición tanto como de la visión. Al mismo tiempo, se agrega un matiz, que evoca de algún modo la discusión del libro VI en torno a las figuras del filósofo y del amante de la opinión; y más atrás, la del libro III y la crítica a la poesía: las audiciones a que aquí se hace alusión, no solo son múltiples y bellas en apariencia, sino que se dan en el marco de un espectáculo teatral, y para alabar algo moralmente falso, o dar la impresión de que es bello lo que de ningún modo lo es.

Esta contextualización de la visión y la audición en el marco del espectáculo se conecta con algunos elementos de la descripción del carácter del hombre tiránico, ya en el libro IX. Como hemos dicho, en este caso el acento de la discusión se pone fuertemente en la inversión que opera

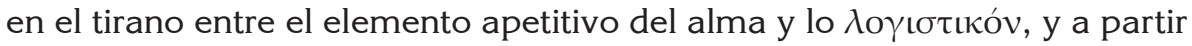
de esta oposición, en la valoración de la vida del tirano y de la polis tiránica como felices o infelices. Dentro de esta sección del diálogo, se describe así cómo un hombre que tiene adecuadamente armonizados los tres elementos de su alma, puede dormir sanamente, evitando las "visiones

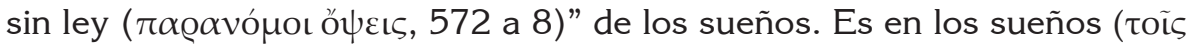

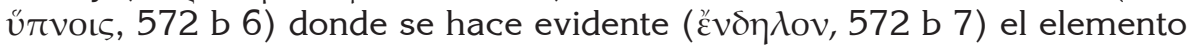
apetitivo (Cf. 572 a y ss). El hijo del gobernante democrático, en su tránsito hacia la tiranía, dará rienda suelta a todos sus deseos, dominado por un Eros tiránico, y utilizará la fuerza para obtenerlos. Cuando en su interior todavía regía la democracia, tenía ciertas opiniones por justas y las opiniones contrarias sólo se liberaban durante la visión onírica (őv $\alpha Q, 574$ d

(2006) sobre la tripartición del alma y sus implicaciones respecto de las capacidades cognitivas de cada uno de sus elementos. 
8), en el sueño ( $\dot{\varepsilon} v \dot{v} \pi v \omega, 574$ e 1$)^{39}$. Ahora, cuando habita en él un Eros totalmente anárquico y anómico ${ }^{40}$, lo que antes pocas veces sucedía en el

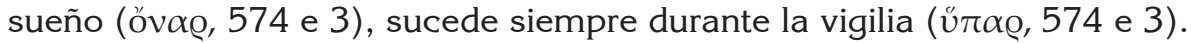
Cabe señalar que los términos usados para oponer sueño y vigilia refieren ambos a un tipo de visión: la visión onírica contrapuesta, precisamente, a lo que se ve estando despierto ${ }^{41}$. Lo significativo es que el tirano ve, en vigilia, lo que en realidad corresponde a óvo@, la visión onírica. El contraste semántico evoca, evidentemente, el pasaje del libro VII, posterior a la alegoría de la caverna, en que se fuerza a los filósofos a gobernar y cuidar de sus conciudadanos, porque así la polis habitará "en la vigilia (út $\alpha \varrho, 520$ c 6)", y no "en el sueño (övaQ, 520 c 7)", como ocurre, según Sócrates, en las mayoría de las ciudades actuales, que compiten entre sí semejantes a sombras. El hombre tiránico invierte, precisamente, sueño y vigilia, viviendo en vigilia como si se tratara de un sueño; representa así un modo de vida opuesto al de aquel que ha ascendido desde la caverna.

Por último, en $579 \mathrm{~b}$, después de haber caracterizado al tirano como un esclavo, se relata cómo, debido al miedo, es incapaz de viajar y "con-

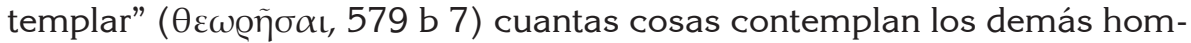

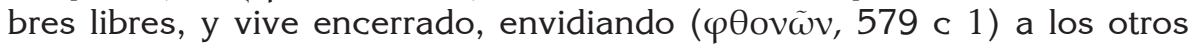
ciudadanos.

Si analizamos en conjunto los elementos referidos a la visión y la audición que forman parte de las descripción de la tiranía y el tirano, podemos afirmar que éste no solo permanece en un nivel de experiencia visual y auditiva exclusivamente sensible, sino que incluso este nivel de experiencia se anula, ya sea porque le es imposible realizarla (cf. el pasaje arriba citado: solo le queda el mirar envidioso, al que ya nos referimos en el análisis de la conversación sobre la oligarquía ${ }^{42}$ ), o porque confunde la experiencia sensible de la realidad con la de los sueños o los espectáculos teatrales ${ }^{43}$, es decir, con un tipo de visión y audición ilusorias incluso en

39 Se desprende del relato, en primer lugar, que los apetitos sin ley habitan en el interior de todos los hombres (incluso en aquellos moderados o virtuosos); la diferencia entre los distintos tipos humanos estriba en que la manifestación de esos apetitos solo se presenta en sueños para la mayoría (solo el tirano, como se verá, lleva la ejecución de estos deseos del plano onírico al real). Por otro lado, y como decimos arriba, el hombre justo puede armonizar el alma de manera que se evite la manifestación de esas visiones incluso en el sueño

40 Así como purifica la ciudad de los mejores hombres, purifica su alma de los deseos moderados, invirtiendo la noción misma de purificación (Cf. Pl. R. 573 b).

41 Cf. LSJ (1991), Chantraine (1968), Ast (1908).

42 Cf. supra, punto 3.

43 Durante toda la sección, además, la falta de visión y audición del tirano se contrasta con el mirar agudo, que va más allá de lo exterior (cf. 577 a y ss), y el hablar melodioso de los interlocutores (cf. 569 c 6). 
el plano sensible ${ }^{44}$. En este sentido, podría pensarse el estado epistemoló-

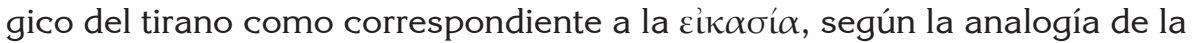
línea en el Libro $\mathrm{VI}^{45}$, que es el nivel cognitivo que jerárquicamente está por

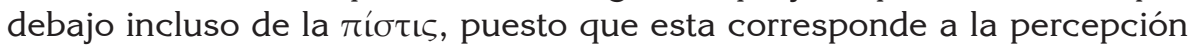
sensorial y aquella a la percepción de reflejos y sombras de lo sensorial ${ }^{46}$.

\section{Conclusiones}

A través de este recorrido filológico hemos intentado mostrar cómo las instancias visual y auditiva son constitutivas del cambio operado en el alma de los gobernantes de cada régimen político, y por lo tanto en el cambio de la politeia misma, ya que el texto propone un paralelismo entre el ethos del hombre y el de la ciudad. Los libros VIII y IX plantean en este marco un recorrido descendente en las formas de organización política, dentro del cual, como se ha visto, se inserta un recorrido, también descendente, por las experiencias humanas de la audición y de la visión. De una audición filosófica, vinculada al ámbito de los logoi verdaderos y a la divinidad de las Musas, se concluye en una audición multiforme de discursos falsos y de diferentes grados de valía, que el oyente es incapaz de distinguir. En el medio, se ha pasado por la dilución de la experiencia visual: desde un ver exclusivamente sensible, se pasa a la situación de ceguera del hombre oligárquico, hasta llegar al impacto visual de la policromía, donde el acento se pone nuevamente en la incapacidad del hombre de jerarquizar y distinguir. Finalmente, con el gobernante tiránico, se llega a la anulación de la experiencia visual y auditiva, reemplazada por la ilusión y el deseo de esta experiencia. En ese camino, la polis entera pierde su concordia, para transformarse en dos poleis, o en toda clase de poleis, y así se desintegra como ciudad.

44 Sobre las imágenes que no imitan las cosas de manera semejante a la realidad en la República, cf. Napolitano (2004).

45 Cf. Pl. R. 511 d-e.

46 Cf. Pl. R. 510 a. Cf. J. Annas (1981: 249-50), sobre el significado de la línea no solo en tanto analogía de la relación inteligible-visible, sino también como representación de los distintos estadios de conocimiento. 


\section{Bibliografía}

\section{Textos}

Platon (1954-1974) Oeuures Completes, Les Belles Lettres, París.

Platone (1993) Fedro, a cura di G. Reale, Milano, Fondazione Lorenzo Valla. Platone (1997) Repubblica, a cura di Mario Vegetti, Laterza, Roma-Bari.

Platone (2001) Simposio, a cura di G. Reale, Milano, Fondazione Lorenzo Valla.

Platone (2003) Timeo, a cura di F. Fronterotta, Milano, Rizzoli.

Rowe, C. (1998) Plato: Symposium, Aris E Phillips.

\section{Bibliografia instrumental}

Ast, F. (1908) Lexicon Platonicum, Hermann Barsdorf Verlag, Berlín, Vol. I- VI.

Chantraine, P. (1968) Dictionaire étimologique de la langue grecque, Klinksieck, París.

LidDell, H. Y R. Scott (1991) A Greek-English Lexicon, ed. Rev. por Sir Henry StUaRt Jones, Clarendon Press, Oxford.

\section{Bibliografía crítica citada}

Annas, J. (1981) An Introduction to Plato's Republic, Oxford University Press.

- (199) Platonic Ethics: Old and New, Ithaca.

Baker, E. (1960,1ra. Ed.1918) Greek Political Theory. Plato and His Predecessors, London- New York.

Catenaro, F. (2013) Il Pensiero Politico in Platone, Teramo, Giacinto Damiani Editore.

Di GiAimo, M. C. (2006) "La música entre información y comprensión en la obra de Platón", en CornavacA, R. et alii, Estudios Platónicos II, Córdoba, Eds. del Copista.

Fernández Rivero, M.c. (2015) Ecos presocráticos en Platón. Ver, oír y conocer en Heráclito, Parménides, Empédocles y Platón, Córdoba, Eds. del Boulevard.

Fronterotta, F., (2003) "Introduzione", en Platone, Timeo, Milano, Rizzoli. GAISER, K., (1998) "Il discorso delle Muse sul fundamento dell'ordine e del disordine", Milano (ed. original alemán 1974). 
Griser, P. (2000) “Visione e conoscenza. Il 'gioco' analógico di Repubblica VI-VII", en CAsertano, G. et alii, La struttura del dialogo platónico, Napoli, Loffredo.

Havelock, E. (1963) Preface to Plato, Cambridge University Press.

Hitz, Z. (2010) "Degenerate Regimes in Plato's Republic", en McPherran, M.

et altr., Plato's Republic: A Critical Guide, Cambridge University Press. Jaeger, W. (1957) Paideia. Los ideales de la cultura griega, México, FCE.

Levin, S. (2014) Plato's Rivalry with Medicine. A struggle and its dissolution, OUP.

Lorenz, H. (2006) The Brute within. Appettive desire in Plato and Aristotle, OUP.

Merker, A. (2003) La visión chez Platon et Aristote, Akademia Verlag- Sankt Augustin.

Meulder, M. (1992) "L'invocation aux Muses et leur réponse (Platon, Républ. VIII, 545 d- 547 c)”, en Revue de Philophie Ancienne, Tome $\mathrm{X}, \mathrm{N} \cong 2$, Bruxelles.

Moutsopoulos, E. (1959) La musique dans l'oeuvre de Platon, Presses Universitaires de France.

Napolitano Valditara, L. (1994) Lo sguardo nel buio. Metafore visive e forme grecoantiche della razionalità, Roma- Bari, Laterza.

(2004) "Platone: illusioni degli occhi, illusioni dell'anima", en BARBANTI, M. et alii, Hénoosis kai philía: Unione e amicizia, Universitá di Catania.

PAQUET, L. (1973) Platon: la médiation du regard, Brill- Leiden.

Racionero, Q. (1998) "Logos, myth and probable discourse in Plato's

Timaeus", Elenchos, Rivista sul pensiero antico, Anno XIV, pp. 29-60.

Reale, G. (2002) Platón. En búsqueda de la sabiduría secreta, Trad. De R.

BERNET, Barcelona, Herder. Ed. original italiano 1998.

Rosen, S. (2005) Plato's Republic. A Study, Yale University Press, LondonNew Haven.

Rowe, C. (2006) "Interpreting Plato", en Benson, H. et alii, A Companion to Plato, Blackwell, Oxford.

SANTA CRuz, M. (2007) "Falsedad genuina y falsedad verbal en Platón", en GonzÁlez De Tobía et. alii, Lenguaje, discurso y civilización, UNLP. SlÉzÁK, TH. (1991) Leer a Platón, Trad. De J. García RúA, Madrid, Alianza. Vegetti, M. (1999) Guida alla lettura della Repubblica di Platone, Bari, Laterza.

Wallach, W. (2001) The Platonic Political Art. A study of Critical Reason and Democracy, Pensylvania University Press.

Fecha de recepción: 11-11-2017

Fecha de aceptación: 26-01-2018 